\title{
Síndrome postcolecistectomía por cálculos biliares caídos
}

\author{
Postcholecystectomy syndrome due to fallen gallstones \\ Juan Ramón y Cajal Calvo,* Pilar Tobajas Morlana, * Roberto Juan Castejón* \\ Citar como: Ramón y Cajal CJ, Tobajas MP, Castejón RJ. Síndrome postcolecistectomía por cálculos biliares \\ caídos. Acta Med GA. 2021; 19 (4): 558-561. https://dx.doi.org/10.35366/102547
}

\section{Resumen}

Introducción: El síndrome postcolecistectomía es un conjunto de síntomas gastrointestinales que pueden ser orgánicos o funcionales y de origen biliar o no biliar. En ciertas ocasiones es producido tiempo después de haberse realizado una colecistectomía laparoscópica, debido a la presencia de cálculos intraperitoneales liberados durante dicha intervención. Caso clínico: Paciente de mediana edad que acude al Servicio de Urgencias por dolor abdominal focalizado en hipocondrio derecho, intervenido de colecistectomía laparoscópica los meses previos. Las pruebas de imagen realizadas ponen de manifiesto la existencia de colecciones heterogéneas con litiasis en su interior de localización subhepática y subfrénica derecha, compatibles con abscesos derivados de litiasis residuales. Es intervenido mediante cirugía con el drenaje y aspiración de dichos abscesos. El síndrome de postcolecistectomía es una condición poco habitual, de sintomatología biliar que sucede en casos con antecedentes de colecistectomía laparoscópica previa. Se requieren estrategias de diagnóstico y tratamiento individualizados para un manejo y resultados óptimos, siendo la cirugía el tratamiento de elección en la mayoría de las ocasiones.

Palabras clave: Síndrome de postcolecistectomía, litiasis, laparoscopia.

\section{INTRODUCCIÓN}

El síndrome postcolecistectomía se caracteriza por la persistencia de síntomas clínicos gastrointestinales, que en ciertas ocasiones pueden acontecer tiempo después de haberse realizado una colecistectomía laparoscópica, debido a la

\section{Abstract}

Introduction: Post-cholecystectomy syndrome is a set of gastrointestinal symptoms that can be organic or functional and of biliary or non-biliary origin. On certain occasions, it occurs some time after having performed a laparoscopic cholecystectomy, due to the presence of intraperitoneal lithiasis released during the said intervention. Clinical case: Middleaged patient who came to the emergency room for abdominal pain focused on the right upper quadrant, who had undergone laparoscopic cholecystectomy months before. The imaging tests were carried out to reveal the existence of heterogeneous collections with lithiasis in their interior in a subhepatic and right subphrenic location, compatible with abscesses derived from residual lithiasis. The patient was intervened by surgery with the drainage and aspiration of said abscesses. Postcolecystectomy syndrome is a common condition of recurrence of biliary symptoms that occurs in patients with a history of previous laparoscopic cholecystectomy. Individualized diagnosis and treatment strategies are required for optimal management and results, depending on the surgical treatment of the majority of cases.

Keywords: Postcholecystectomy syndrome, lithiasis, laparoscopy.

presencia de cálculos intraperitoneales liberados durante la intervención.

Los síntomas clínicos son inespecíficos, presentando dolor abdominal difuso o en hipocondrio derecho, así como distensión abdominal en personas con antecedentes de colecistectomía.

\footnotetext{
* Servicio de Radiodiagnóstico. Hospital Clínico Universitario "Lozano Blesa". Zaragoza, España.
}

www.medigraphic.com/actamedica
Correspondencia:

Juan Ramón y Cajal Calvo

Correo electrónico: jramonycajalı@gmail.com

Aceptado: 14-06-2021.

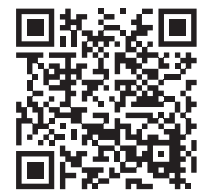


Presentamos el caso clínico de un paciente con un síndrome de postcolecistectomía, el cual fue diagnosticado de manera correcta gracias a los hallazgos en las pruebas de imagen durante el ingreso, sumado al antecedente quirúrgico previo, presentando una satisfactoria evolución tras la reintervención con drenaje y lavado abdominal al que fue sometido.

\section{CASO CLÍNICO}

Se presenta un paciente de 48 años, que acude al Servicio de Urgencias de nuestro centro hospitalario por la presencia de picos febriles de hasta $39^{\circ} \mathrm{C}$ de predominio vespertino de tres días de evolución, acompañado de dolor en hipocondrio derecho.

Refiere como único antecedente quirúrgico una colecistectomía laparoscópica seis meses antes por la presencia de un cólico biliar complicado. Desde entonces relata dolor en el hipocondrio derecho que ha requerido el seguimiento por parte del Servicio de Cirugía General, estando a la espera de una tomografía axial computarizada (TAC) abdominal programada.

A la exploración física, el abdomen se encuentra blando, depresible y doloroso a la palpación de mesogastrio e hipocondrio derecho, con la presencia de signo de Murphy positivo. El resto de exploración física y valores analíticos no demuestran ninguna alteración significativa.

Se decide realizar pruebas complementarias de imagen, comenzando por una ecografía abdominal que evidencia una lesión heterogénea bien delimitada con calcificaciones en su interior ubicada en el lóbulo hepático derecho, lo cual plantea como primera opción diagnóstica la existencia de un absceso hepático (Figura 1). Ante la existencia de la lesión y la persistencia de la clínica, se decide ampliar el estudio mediante una TAC de urgencia para una mejor filiación de la misma. Se realiza una TAC abdominal con contraste intravenoso que pone de manifiesto la existencia de un discreto derrame pleural derecho, así como de una lesión de morfología ovalada con imágenes de densidad cálcica en su interior localizada en el espacio subfrénico derecho, y afectación hepática en el segmento VIII compatible con absceso o colección inflamatoria en dicho nivel. En el lecho quirúrgico de la colecistectomía se visualiza una imagen de predominio líquido, mal definida, que también presenta en su interior la presencia de litiasis (Figura 2).

Los hallazgos radiológicos y los antecedentes quirúrgicos del caso son compatibles con el síndrome de postcolecistectomía por litiasis residuales y afectación inflamatoria secundaria.

Se decide llevar a cabo una intervención quirúrgica por parte del servicio de cirugía general de nuestro centro, realizándose una laparoscopia exploradora que permite el drenaje de ambas colecciones, así como la extracción y aspiración de las litiasis existentes (dos en el espacio subfrénico y tres en el lecho vesicular) (Figura 3).

La evolución postoperatoria es favorable, siendo dado de alta hospitalaria a los pocos días de la intervención debido a la mejoría y estabilidad clínica.

\section{DISCUSIÓN}

El síndrome postcolecistectomía se puede definir como la falta de mejoría o recurrencia de la sintomatología tras la realización de la exéresis de la vesícula biliar, tanto de forma urgente como programada.

La colecistectomía laparoscópica es una técnica frecuente en pacientes con alta prevalencia de colelitiasis que relatan clínica vesicular. Las ventajas respecto a la colecistectomía vía abierta son: menos complicaciones postoperatorias, menor estancia hospitalaria y una rápida recuperación, siendo un procedimiento con mejor rentabilidad desde el punto de vista económico. ${ }^{2}$

La perforación iatrogénica vesicular durante la colecistectomía laparoscópica es bastante frecuente, cuya incidencia varía entre 15 y 40\%, ${ }^{3}$ asociando caída de cálculos a la cavidad abdominal en un 5-7\% de los casos, también denominados cálculos abandonados, siendo más usual en la técnica por vía laparoscópica.

Las complicaciones por la presencia de cálculos abandonados intraperitoneales no son habituales, aunque

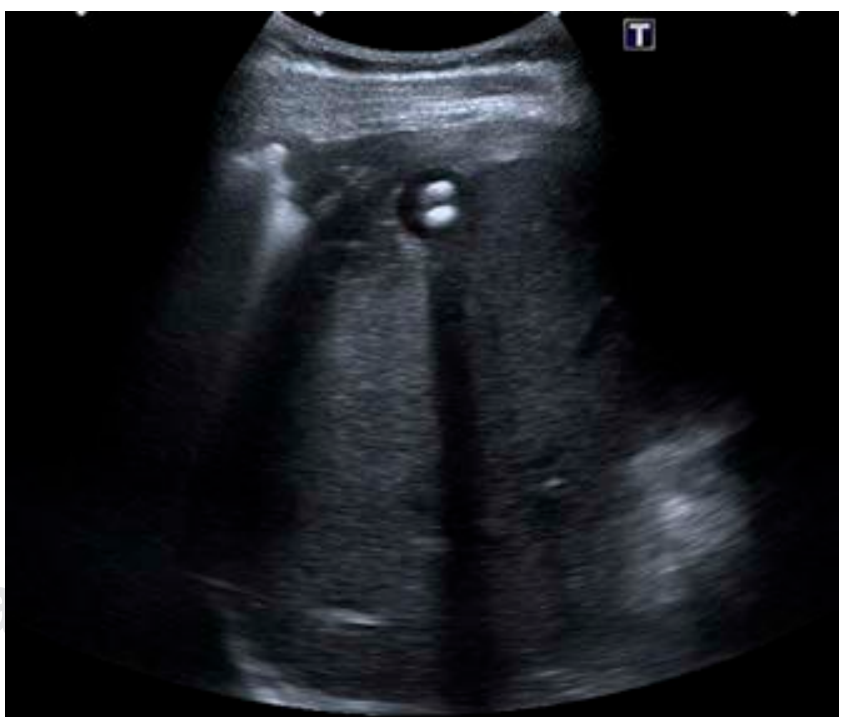

Figura 1: Ecografía abdominal que pone de manifiesto en el lóbulo hepático derecho la existencia de una imagen redondeada bien delimitada hipoecogénica con dos imágenes hiperecogénicas con sombra acústica posterior en su interior compatibles con litiasis residuales. 

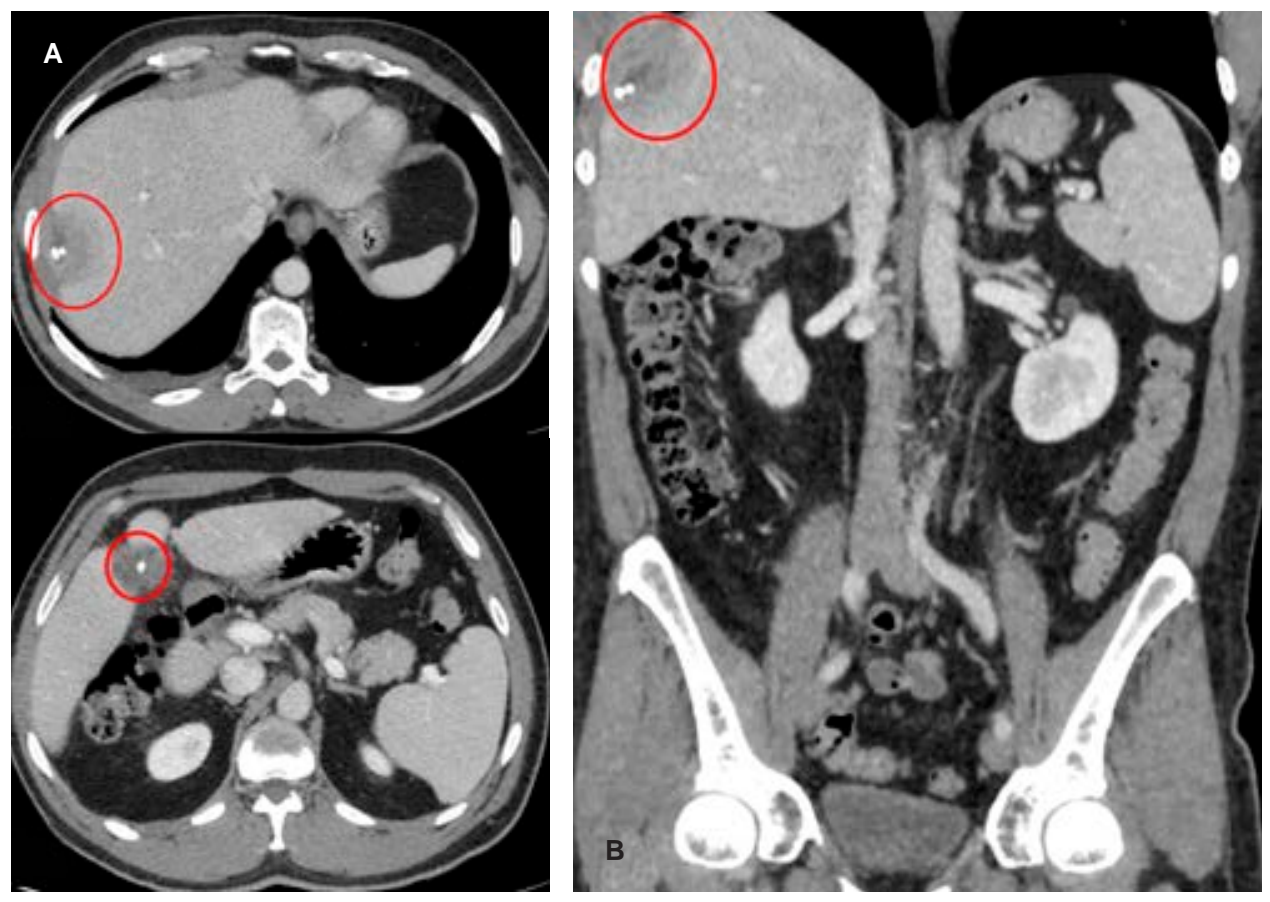

Figura 2:

A) Tomografía axial computarizada abdominal, cortes axiales, B) Coronal. Se objetiva colección heterogénea a nivel del segmento VIII hepático, visualizado en la ecografía mostrada en la Figura 1, correspondiente con absceso hepático con litiasis residuales en su interior (círculo rojo). También se localiza otra colección con litiasis en el lecho vesicular (Figura 2B).

pueden conllevar consecuencias que derivan en una alta comorbilidad y mortalidad. Una de las complicaciones más frecuentes es el absceso intraabdominal, el subhepático y subfrénico son los más comúnes. Otras posibles complicaciones incluyen la infección de la herida quirúrgica, obstrucción o perforación intestinal, senos cutáneos, adherencias, fístulas e ictericia. El tiempo de aparición de la sintomatología es diverso, pueden ser meses o incluso años. ${ }^{4}$

Si hablamos de la fisiopatología de los abscesos abdominales, se propone que los cálculos abandonados actúan como cuerpos extraños, los cuales se pueden infectar, conduciendo a la formación de un proceso inflamatorio en dicha zona. Los microorganismos más habitables que se han cultivado y reportado asociados con los abscesos originados por cálculos abandonados son Escherichia coli, Klebsiella pneumoniae, Streptococcus milleri y Pseudomona aeruginosa..$^{5}$

El diagnóstico diferencial incluye el absceso hepático, actinomicosis hepática, neoplasia o peritonitis; sin embargo, el antecedente quirúrgico previo y la presencia de calcificación favorecen el diagnóstico de cálculo abandonado.

Los hallazgos radiológicos son fundamentales a la hora del diagnóstico definitivo. La ecografía abdominal manifiesta imágenes nodulares o lineales hiperecogénicas con sombra acústica posterior correspondientes con litiasis. La TAC mostrará lesiones heterogéneas de predominio hipodenso, con calcificaciones en su interior y realce

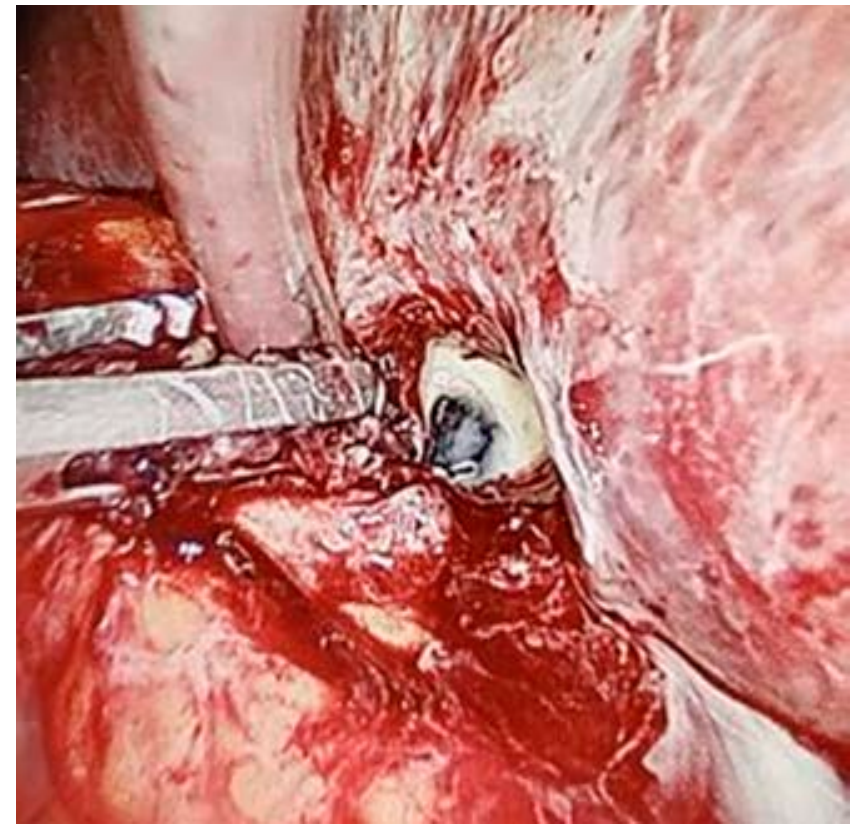

Figura 3: Hallazgos intraoperatorios. Laparoscopia exploradora donde se objetivan litiasis residuales a nivel del segmento VIII hepático rodeados de una colección purulenta subyacente.

periférico tras la administración de contraste intravenoso, con la presencia de líquido libre en espacio de Morrison o en el espacio subhepático en relación con las colecciones generadas alrededor de los cálculos abandonados. 


\section{CONCLUSIONES}

El tratamiento de las complicaciones relacionadas con el síndrome de postcolecistectomía depende de la sintomatología generada; no obstante, $90 \%$ de los pacientes precisan de un procedimiento quirúrgico para el drenaje del absceso intraabdominal y la extracción de los cálculos, para evitar futuras recurrencias, además, es fundamental que el cirujano reconozca una perforación durante la realización de una colecistectomía y trate de extraer todos los cálculos libres junto con un minucioso lavado de la cavidad abdominal.

La historia clínica del paciente, así como la demostración de las imágenes radiológicas características, permiten llegar a un diagnóstico de presunción. Una estrategia de tratamiento y manejo individual con un enfoque quirúrgico selectivo con un extenso lavado de la cavidad es el procedimiento de elección.

\section{REFERENCIAS}

1. Castellón-Pavón CJ, Morales-Artero S, Martínez-Pozuelo A, Valderrábano-González S. Complicaciones por cálculos y clips intraabdominales abandonados durante una colecistectomía laparoscópica. Cir Esp. 2008; 84 (1): 3-9.

2. Khan M, Khatri M, Oonwala Z. Knowledge and practices of general surgeons and residents regarding spilled gallstones lost during laparoscopic cholecystectomy: a cross sectional survey. Patient Saf Surg. 2013; 7 (1): 27.

3. Pérez JM, Araújo AAB, Pérez C, Forero J, Grillo CPA, Riascos CEY et al. Hallazgos imagenológicos en cálculos abandonados en cavidad abdominal posterior a colecistectomía por laparoscopia: serie de 7 casos y revisión de la literatura. Rev Colomb Gastroenterol. 2007; 32 (3): 274-282.

4. Castellón PCJ, Fernández BM, Morales AS, Del Amo OE. Absceso subhepático como complicación tardía de un cálculo intraperitoneal abandonando tras una colecistectomía laparoscópica. Gastronenterol Hepatol. 2004; 27 (10): 568-572.

5. Gayer G, Petrovitch I, Jeffrey RB. Foreign objects encountered in the abdominal cavity at CT. Radiographics. 2011; 31 (2): 409-428. 